\title{
EVOLUCIÓN HISTÓRICA DE LA AUDITORÍA AMBIENTAL EN EL SIGLO XXI. EL CASO CUBANO ${ }^{1}$
}

\author{
Historic evolution of the environmental auditing in the century \\ XXI. The case cuban
}

\author{
Alcides Francisco Antúnez Sánchez \\ Profesor Auxiliar Derecho Ambiental y Derecho Internacional \\ Facultad de Ciencias Económicas y Sociales \\ Universidad de Granma, República de Cuba \\ aantunez@udg.co.cu
}

Recibido: 15/06/2020 - Aceptado: 07/09/2020

\section{Resumen}

A escala global, aprovechar las potencialidades energéticas que el ambiente aporta al hombre sigue siendo un reto para la comunidad científica. Los gobiernos implementan estrategias que fomentan el incremento de parques eólicos, el uso de celdas fotovoltaicas a través de paneles solares, e

- Palabras clave: Energía eólica; Energía hídrica; Energía solar; Ciclo de vida hidroeléctricas para la obtención de energía que aporta el agua, para el uso del consumo humano a través de la red eléctrica. Empero, para conseguir este fin, se hace indispensable, la publicación por parte de los Estados de cuerpos legales en los ordenamientos jurídicos que ofrezcan incentivos dirigidos a la producción de energía a partir del uso de las fuentes renovables, y el diseño de estrategias de desarrollo con el uso de los avances científicos para modificar la matriz energética, no solo a nivel regional, sino a nivel nacional, de manera que sea creciente su aporte a para lograr una matriz energética sostenible en consonancia con los Objetivos del Milenio para el 2030.

\begin{abstract}
To global scale, to make good use of the energetic potentialities that the environment contributes to the man continues to be a challenge for the scientific community. The Governments implement strategies that foment the increment of wind farms, the use of photovoltaic cells through solar panels, and hydroelectric for the obtaining of energy that you

1 La investigación está vinculada al Proyecto empresarial sobre Capacitación jurídica a los Consultores Jurídicos de la Empresa de Servicios Legales de la provincia Granma, desarrollado por la carrera de Derecho de la Universidad de Granma. Email: aantunez@udg.co.cu, antunez63@nauta.cu__ORCID No.0000-0002-8561-6837.
\end{abstract}


contribute the water, for the use of the human consumption through the electric net. Yet, in order to get this end, you become indispensable, the publication for part of the States of

\section{- Keywords:}

Aeolian energy; Hydric energy; Solar energy; Cycle of life bodies of laws that offer guided incentives the production of energy as from the use of the renewable sources in the juridical organizings, and the design of strategies of development with the use of the scientific advances to modify the energetic womb, you did not sole regional level, but nationally, so that his contribution be increasing to for to achieve an energetic sustainable matrix in consonance with the Objectives of the Millennium for 2030.

\section{Material y métodos}

El artículo propone como objetivo caracterizar el campo de acción de la auditoría ambiental en los diferentes escenarios donde se ejecuta por el equipo auditor de la Entidad Fiscalizadora Superior en las etapas estudiadas de la auditoría ambiental en Cuba hasta el siglo XXI. Se parte para ello desde su origen, desarrollo, y evolución de su tratamiento teórico doctrinal, y como se ha regulado en la legislación hasta el siglo XXI, concluyendo con el control ejecutado a las energías renovables por las formas de gestión que la implementan para mitigar la contaminación y alcanzar el desarrollo sostenible al modificarse la matriz energética en relación a los Objetivos del Milenio para el 2030. Se formula la hipótesis del diseño de la investigación, no experimental con enfoque cualitativo. Para ello, se han utilizado los métodos de la investigación como el de análisis síntesis, histórico comparado, revisión bibliográfica, e inducción deducción.

1. Introducción - 2. La auditoría ambiental, origen, evolución y desarrollo en el campo del control público - 3. La auditoría como actividad de control ambiental en el campo de acción en el sector empresarial 4. La auditoría ambiental, campos de aplicación en la protección del ambiente - 5. La auditoría ambiental aplicada como evaluadora a las fuentes renovables de energía: 5.1. Las energías renovables, su uso, implementación y regulación en el ordenamiento jurídico cubano a partir del control público ambiental -6 . Conclusiones - Bibliografía

\section{INTRODUCCIÓN}

El problema de la energía y el ahorro energético se convierte hoy en un problema relevante a tener en cuenta en el siglo XXI. La energía se obtiene a partir de las fuentes de energía y las cantidades disponibles de dichas fuentes es lo que se denomina recursos energéticos que los recursos naturales le aportan al hombre en su relación difusa con la naturaleza.

Cambiar la explotación de los recursos finitos constituye un reto para la Administración Pública, para ello fomenta el uso de las fuentes de energías renovables, a partir del uso de la energía solar fotovoltaica, eólica, geotérmica, termosolar, hidroeléctrica, bioenergía y el poder de las corrientes marinas, siendo un tema recurrente en las políticas públicas en Cuba. 
En consecuencia, el avance que han experimentado el uso de estas energías se ha extendido globalmente en el actual siglo, por estar disponibles en todo el mundo, al contrario que las tradicionales como el gas, carbón y petróleo, las cuales se concentran en algunos países en concreto y son finitas.

Los estudios realizados en el mundo académico ponderan que el uso de las energías renovables, lo cual permite obtener energías más limpias, las que no generan desechos peligrosos, son fáciles de desmontar, aumentan la autonomía en las regiones, generan puestos de trabajos verdes, concebidas como energías seguras, y son fuentes inagotables en su uso y explotación por el hombre en su relación con el ambiente.

Ha dado lugar desde la ciencia social del Derecho, al avance y aplicación del Derecho Internacional Energético al ser los Tratados su núcleo duro, desarrollado como una nueva rama del Derecho, para ello el Derecho Energético tiene como objeto ordenar y regular en su amplio espectro el comercio internacional de la energía. Por la complejidad y amplia variedad de su objeto de regulación, el Derecho Internacional de la Energía abarca campos y aspectos del Derecho Internacional Público y del Derecho Internacional Privado, del Derecho Económico, Mercantil, Administrativo, Ambiental, Fiscal y el Derecho Constitucional.

De ahí que, en los últimos años, una importante corriente doctrinal latinoamericana y otras como la española, la francesa y la italiana, se pronuncien por el manejo del término conceptual de Derecho Internacional de la Energía y de los productos básicos, lo que los juristas ingleses han dado en llamar "Internacional Law of Energy and Raw Materials".

Desde el Derecho Administrativo Ambiental, la actividad de control -auditoría ambiental- aparece para que la Administración Pública pueda conocer el grado de cumplimiento de las políticas públicas y evaluar el cumplimiento de la legalidad de las normas en el orden ambiental, incidentes en lograr alcanzar el desarrollo sostenible en atención a los Objetivos del Milenio para el 2030 pertinentes para el ahorro y la eficiencia energética al fomentarse el uso de la energía verde.

\section{LA AUDITORÍA AMBIENTAL, ORIGEN, EVOLUCIÓN Y DESARROLLO EN EL CAMPO DEL CONTROL PÚBLICO}

Para analizar la auditoría ambiental, es preciso iniciar su estudio desde los orígenes de la auditoría como hoy se le conoce "actividad de control"; la historia devela que se remonta su hacer al Egipto antiguo, donde los soberanos para evitar desfalcos en las cuentas de sus residencias o en la construcción de obras públicas aplicaban medidas de control. Esta práctica en materia de control, estuvo presente en las civilizaciones antiguas, la que desaparece junto con el mercado y el sistema monetario al finalizar esta etapa histórica y comenzar la Alta Edad Media, caracterizada por el predominio de la economía natural (VILLARDEFRANCOS ÁlVAREZ et al., 2006, pp. 53-59). 
Al estudiar la institución jurídica de la auditoría, es pertinente visualizarla en la época posterior a la invención de la escritura, aunque su práctica proceda de civilizaciones tan antiguas como la egipcia, en la que se procedía a controlar los ingresos de los impuestos y los gastos, subdividiendo la tarea entre recaudadores distintos, conociendo cada uno de ellos que su labor sería revisada con posterioridad por un funcionario distinto, para determinar el honesto manejo de los mismos como por los recaudadores encargados de estas funciones.

En esta época estudiada, el pueblo era sometido al pago de tributos por el soberano que lo dominaba, se conoce como contribución (impuesto); para su control se designaban revisores, quienes realizaban la actividad de fiscalización para la administración de sus riquezas, se evidencia también esta práctica en la civilización del pueblo Sumerio, en los años 3300 antes de Cristo.

En Europa, en las naciones de Inglaterra y Escocia en 1130, se comenzó el uso de los llamados Registros de los Erarios, como una especie de registro contable. Se signa que el título de Auditor fue para las personas que dominaban esta técnica, iniciándose las asociaciones de estos profesionales en el Colegio de Contadores de Venecia en Italia, los Consejos Londinenses en Inglaterra y el Tribunal de Cuentas de París.

En Gran Bretaña, BARreiro ZABAlA (1922, p.4) en sus estudios refiere “...la inspección de cuentas o libros data de época muy remota. En el año 1299, según se lee en los archivos del Ayuntamiento de Londres, se nombraba una persona que ejercía el cargo de Auditor o Inspector para que revisara las cuentas de aquel municipio...".

La razón de ser Gran Bretaña, la cuna de la institución jurídica de la auditoría, se explica por ser el país pionero en la Revolución Industrial, precursor y máximo exponente de las técnicas de auditoría en su desarrollo, cuestión que se debe a dos causas, por un lado: al alto nivel del desarrollo industrial y financiero, y haber contado con la experiencia de siglos de los Consejos Londinenses, precursores de las actuales asociaciones profesionales de auditores (VILlARDEFRANCOS ÁlVAREZ et al., 2006, pp. 53-59).

En el resto de los países europeos, se introdujeron estos medios de control en la época del Renacimiento. A partir del siglo XII, en el período de Baja Edad Media, trajo consigo el resurgimiento de las ciudades, el florecimiento de los oficios y el desarrollo del comercio, los que exigían determinados tipos de evidencia documental en la actividad mercantil.

BALlesteros \& MARÍN-BALdo (1924, p. 24) son del criterio que hacia el siglo XIII se generaliza el uso del papel, aquí en este momento histórico, pudo obtener la contabilidad sensibles progresos. Más tarde, ya avanzado el siglo XVII, la Ordenanza francesa de 1673, perfiló la obligación de conservar y transcribir en un libro los aspectos contables, formulándose semestralmente los inventarios.

En España, país que cuenta con la legislación sobre el tema analizado más antigua del mundo, dispone la obligatoriedad para todos los comerciantes y banqueros, nacionales 
o extranjeros, residentes en los reinos de Castilla, de llevar sus cuentas por el sistema de partida doble. Así, el origen de la auditoría es corroborado en el Tribunal de Cuentas de España, y se remonta a los tiempos de Sancho IV el Bravo, Rey de Castilla y León (1284-1295), pocos años después surgía en Navarra bajo el reinado de Carlos II, el Malo, una institución de características similares, donde la Cámara, especie de consejo real para asuntos económicos tuvo facultades como Tribunal de Cuentas (MARTÍNEZ GARCÍA, 1992, p. 62).

Se aprecia que, el motivo de la creación de estas instituciones jurídicas como las Cortes de Toledo, celebradas en 1436, cuyo fin era auditar las cuentas públicas por los Contadores Mayores en el fondo el despilfarro público el que acaban pagando los contribuyentes por medio de los impuestos. Siguiendo este estudio para caracterizar a la función auditora, se corrobora que a finales del siglo XIII y principios del XIV ya se auditaban las operaciones de los funcionarios públicos que tenían a su cargo los fondos del Estado para su control público.

En Italia, en el siglo XV, en el desarrollo de la actividad de la auditoría surgieron las técnicas de teneduría de libros, como el medio de mantener los ingresos y los gastos bajo el control público. En la ciudad de Roma, se aprecian evidencias que se practicó una especie de control preventivo en la administración de los fondos públicos, siendo en la época del Imperio de Augusto, años antes del nacimiento de Jesucristo, cuando alcanza su plenitud. Los romanos recaudaban sus tributos por medio de sus "Cuestores", que a su vez rendían cuentas al Tesorero central de Roma.

El referente de la obra científica de LUCAS PACCIOLI (1494) "Tratado sobre el Método" conocido de la "partida doble", evidencia que desde el año 254 se inspeccionaban y comprobaban las cuentas, factor que permitió la evolución paralela de la actividad de la auditoría como resultado de la práctica de la contabilidad como ciencia, y a la vez como herramienta de trabajo de los especialistas dedicados a la contabilidad con el desarrollo del comercio (TUA PEREDA, 2008, pp. 1-23).

El estudio demuestra que para 1799, ya existían firmas acreditadas de contadores públicos en Escocia, Estados Unidos de América e Inglaterra, fueron estas las primeras naciones en las que toma relevancia la función de la contaduría pública ligada a la práctica de la auditoría pública. Las mismas adoptaron el modelo británico de información, lo mismo que sus procedimientos analíticos (TUA PEREDA, 2012, pp. 94-110).

Se aprecia en este análisis como GIRONELLA MASGRAU (1976, p. 15) señala que la historia refiere que existían unos controles recaudatorios en otras civilizaciones, en el Imperio Chino y Mesopotamia. No obstante, el autor consultado indica que la auditoría tal como se concibe actualmente, como una función de validación de los estados financieros, nació en los inicios del siglo XIX en Gran Bretaña.

Otro aporte es el de SUÁREZ SUÁREZ (1990, p. 3), quien considera desde su postura que, la auditoría tal como hoy en día se concibe, en su acepción restringida o verdadera auditoría, consiste en la comprobación de la veracidad de la información contable, no 
nace en Europa hasta después de la Revolución Industrial; en pleno siglo XIX, tuvo un desarrollo muy desigual en unos y otros países inicia su irradiación.

Ilustra este autor consultado, sobre la función de auditor, al observar que en España se le denomina "Auditor de Rota" a cada uno de dos doce prelados del tribunal romano de la Rota, que tiene jurisdicción para conocer en apelación de las causas eclesiásticas; auditor conventual, al religioso encargado de examinar las cuentas del monasterio; auditor militar, al funcionario del cuerpo jurídico-militar que informa sobre la interpretación y aplicación de las leyes, y propone la resolución correspondiente en los procedimientos judiciales instruidos por el ejército; "Auditor de la Marina", al juez letrado que entiende en las causas del fuero del mar; "Auditor Canónico", a la persona designada instructor en las causas canónicas.

En la región de Centroamérica, el antecedente de la auditoría se aprecia en la nación de México, donde el pueblo Azteca se caracterizó por la dominación de otros pueblos, actividad que hacían mediante la contribución a través del recaudador o auditor para explotarlos mediante el cobro de impuestos.

Por ello, por la transdisciplinariedad del tema, desde las ciencias contables, por el vínculo con la función de control estudiada, los estudios refieren que la práctica de la auditoría nace en la primera mitad del siglo XIX, luego se extendió a países de la cultura empresarial anglosajona como la forma de hacer fiable la información contable, permitió la transparencia del mercado de valores ante el desarrollo económico y la expansión de las relaciones económicas al exigirse información precisa y real de sus estados de cuentas, para dar confianza y competitividad a la actividad comercial. Ilustran los elementos estudiados que, el acto de rendir cuentas supone la existencia de un principio de contabilidad crítica: el examen por un funcionario superior de las operaciones económico-financieras realizadas por otro funcionario de inferior categoría, a fin de otorgarles su aprobación o desestimarlas (VILlARDEFRANCOS ÁlVAREZ et al., 2006, pp. 53-59).

Por consiguiente, hasta el suceso histórico de la Revolución Industrial, se demuestra que la economía se desarrollaba en base a una estructura de empresa familiar donde la propiedad y la dirección de sus negocios confluían en las mismas personas, que no sentían ninguna necesidad de la auditoría independiente ni tampoco se les imponía por normativa legal. Como acontecimiento económico social del siglo XIX, fue el suceso histórico cultural que demandó la participación de hombres especializados en analizar los problemas económicos, financieros y contables para su evaluación, donde se necesitó de la contaduría pública como la herramienta técnica para estos fines (MÉNDEZ-GutiÉRREZ DEL VALLE, 2009, pp. 55-56).

Vinculada a las ciencias jurídicas, se constata como en los países de cultura latina, en particular en España, el uso de la auditoría como actividad de control quedó relegada hasta comienzos del siglo XX en el Derecho Militar y en el Derecho Canónico. Se aprecia, cómo fueron incluidas normas jurídicas a la actividad de la auditoría como voluntad de la Administración Pública, elementos que permitieron que se fortaleciera el trinomio Contabilidad, Auditoría y Derecho, al cobrar nuevas dimensiones como norma administrativa para proteger los activos contra posibles transgresiones, 
tipificándose con la protección del bien jurídico ambiental y otras infracciones, ubicados bajo el término genérico de los delitos ambientales con reflejo en la contabilidad directa o indirecta a los sujetos de gestión, fortalecida con el uso de las herramientas de las Tecnologías de la Informática y las Comunicaciones (TIC), la que tuvo como su campo de acción a la empresa (ANTÚNEZ SÁNCHEZ, 2019).

En contexto, RodrígueZ-Flores De QuiÑOnes (1964, p. 169) explícita desde su postura que, para los juristas y hace referencia a España, ignoran la contabilidad, minimizan su importancia y no tienen presentes las bases fundamentales de esta disciplina al tratar de solucionar los problemas que plantean en esta materia. Este elemento ha influido en la jurisprudencia de los Tribunales y se ha reflejado en la legislación, que con frecuencia contienen errores en materia contable. La doctrina contable desconoce en la mayor parte de los casos, los principios más esenciales de la ciencia del Derecho y de la Hermenéutica jurídica.

En su postura, VICENT CHULIA (2010, p. 7711) manifiesta que la contabilidad y el Derecho como ciencias van en un divorcio histórico. Aunque se reconoce que la correcta actualización de la contabilidad es manifestación de una buena organización empresarial, el Derecho Mercantil la ha fomentado tradicionalmente mediante el reconocimiento de los asientos contables como una prueba privilegiada. Por la transversalidad del tema analizado, el aporte con una visión de futuro, realizado desde el Derecho Mercantil por ViCENT CHULia (2010, pp. 115-146), al señalar al control contable, como el término verificación y la expresión de auditoría. Cuestión a la que los autores se afilian, hoy reconocido como Derecho Contable.

La idea aportada en este análisis por BROSETA PONS (2010, p. 292), al referir desde su postura sobre la censura de cuentas, quien señala que, al ser una denominación castellana, la auditoría de cuentas es la denominación importada de la práctica anglosajona. De aquí que se visualice, analizado el parecer de ambos catedráticos estudiados, consideran los autores del artículo su nexo con el Derecho, y en especial con el Derecho Mercantil, hoy señalado en la literatura científica como Derecho Contable para su aplicación por los empresarios para conocer sus estados de cuentas de su patrimonio.

También se valora que, la auditoría tiene un reconocimiento jurídico desde el Derecho Internacional Público, al ser su paraguas, irradiándolo hacia el Derecho Administrativo y al Derecho Constitucional, los que le dan fuerza jurídica para su desarrollo en los ordenamientos jurídicos en cuerpos jurídicos especiales para ejecutarla en el sector empresarial público y el privado por las Entidades Fiscalizadoras Superiores (EFS).

\section{LA AUDITORÍA COMO ACTIVIDAD DE CONTROL AMBIENTAL EN EL CAMPO DE ACCIÓN EN EL SECTOR EMPRESARIAL}

En el propio siglo XX, prosiguiendo el íter histórico de este estudio, se asevera que la auditoría ambiental aparece dentro de los mecanismos de control público con otro 
nuevo campo "el ambiental", se justiprecia que significó un escalón superior en el orden de integralidad, porque apuntó no solo a la eficiencia económica sino a la conformación de la empresa responsable con el ambiente. Representó impulsar y verificar el debido engranaje optimización, legitimidad, racionalidad y competitividad a los sujetos de gestión que la ponderan en la empresa o la industria.

Elementos que a criterio del articulista han sido pertinentes, $\mathrm{y}$ han permitido que haya evolucionado la auditoría ambiental con el transcurso del tiempo en relación con el país que la aplique y el desarrollo tecnológico industrial que posea en su desarrollo normativo con un fin, disminuir la contaminación ambiental que generan los sujetos de gestión económico, como es el objeto central del artículo.

La auditoría ambiental, se corrobora como se instrumenta en los países de mayor desarrollo industrial a través de metodologías y técnicas en sus ordenamientos jurídicos. $\mathrm{Su}$ ordenación se vincula a elementos históricos, teóricos, doctrinales, legislativos y culturales con la práctica de la auditoría y la contabilidad social, ligados a la responsabilidad social a partir de 1953 en los Estados Unidos de América (BOWEN, 1953, pp. 7-47; ROMANQUE, 1996, pp.133-160; GARCÍA FrONTI, 1997, pp. 55-77).

Su conexión como se refirió, está relacionada a los orígenes del ius ambientalismo como parte de la Agenda Pública Internacional desde la impronta del Derecho Internacional. Las Entidades Fiscalizadoras Superiores (EFS) a escala global señalan al año 1969, como su inicio. Se inserta este tipo de auditoría entre los factores de estimulación de fórmulas empresariales correspondiente a la resolución de la contradicción eje de los modelos económicos: ilimitadas necesidades individuales y colectivas y limitados recursos materiales disponibles para satisfacerlas a partir del desarrollo sostenible. Donde como tradición la relación entre la empresa-ambiente ha sido bastante conflictiva: los principales daños ambientales los acarrea la empresa y ésta ha percibido la atención ambiental como un obstáculo en sus actividades y un freno para su desarrollo y obtención de ganancias (LOPERENA ROTA, 2003, pp. 57-73; Allí ArANGUREN, 2006, pp. 1-34; ANTÚNEZ SÁNCHEZ, 2019).

En la década de los 70' del siglo pasado, se constata como el empresariado norteamericano es el primero en aplicarla de manera voluntaria, para evaluar la empresa con la finalidad de servir como herramienta de dirección para la gestión ambiental, todo ello debido al aumento y la complejidad de la normativa jurídica Estadual y Federal en su ordenamiento jurídico, ante los problemas ambientales que acontecían generados por la contaminación al ambiente, los que habían originado problemas en el orden legal (HARRISON, 1996, pp. 1-676).

Estos elementos señalados up supra, se justiprecia que han obligado a los empresarios a replantearse una actitud estratégica hacia la protección del ambiente, con una actitud proambiental para hacer competitiva la empresa en el mercado y mitigar los efectos negativos que tiene la contaminación ambiental con una visión transdisciplinaria.

Las EFS organización internacional creadora de este tipo de auditoría, le concede la función de dar a conocer los índices de contaminación generados como resultado de 
la producción industrial de bienes y servicios, al estimular la implementación de las tecnologías limpias, los sistemas de gestión ambiental y otros instrumentos en materia contable, para obtener la certificación ambiental a partir de la década de los 90' del pasado siglo a los empresarios que la ponderan en empresas e industrias.

Se concibe por ello que, implementar la auditoría ambiental fue una respuesta estratégica para modificar los hábitos de consumo y estilos de vida contrarios al paradigma jurídico del desarrollo sostenible por parte de los empresarios, como el efecto negativo del desarrollo tecnológico y las transformaciones económico-sociales. Trajo como resultado, el reto a las EFS de crear instrumentos y herramientas que viabilizaran su aplicación y permitieran el equilibrio entre los avances tecnológicos y el ambiente por su dimensión multidisciplinaria.

Desde las ciencias jurídicas, en particular desde el Derecho Ambiental Internacional, la auditoría ambiental se reconoce como una herramienta de gestión dentro de los instrumentos de tutela ambiental, se implementa para minimizar los impactos ambientales negativos generados. Es una estrategia empresarial aplicada por la Administración Pública para proteger el bien jurídico público ambiente ante la problemática del cambio climático; se vincula en su ejecución con otras herramientas de gestión con la Evaluación de Impacto Ambiental, la Inspección Ambiental y la Licencia Ambiental, entre otras, de aquí su transversalidad por sus ejecutantes (ANTÚNEZ SÁNCHEZ, 2019).

Por ello, en la década de los 80', del siglo pasado, la Cámara Internacional de Comercio (1986), la reconoce como la “...herramienta de gestión que comprende una evaluación sistemática, documentada, periódica y objetiva del funcionamiento de la organización ambiental. Prevé la implantación de gestión, así como los equipos de control necesarios con objeto de facilitar el control de gestión de las prácticas medio ambientales y declarar la observancia de la política de la Compañía de acuerdo con la normativa ambiental. Es el examen metódico que implica análisis y comprobaciones de las prácticas y procederes ambientales de una empresa o parte de ella. Este término de auditoría es sinónimo de revisión y verificación de diversos aspectos de una empresa...".

La Asociación Americana de Contabilidad, la concibe como “...proceso sistemático para obtener y evaluar de manera objetiva las evidencias relacionadas con informes sobre actividades económicas y otros hechos relacionados. Su finalidad consiste en determinar el grado de correspondencia del contenido informativo con las evidencias que le dieron origen para determinar si en dichos informes se han elaborado con la observancia de los principios establecidos para el caso..." (ALVARADO RIQUELME et al., 2014, pp. 1-507).

En la propia década de los 90' del siglo pasado, prosiguiendo este estudio, se observa como se le adicionan nuevos elementos tecnológicos vinculados al Comercio Internacional a la actividad de control analizada, la hacen mucho más compleja, completa y dinámica en cuanto a la gestión ambiental por parte de los sujetos económicos que la implementan; las técnicas, métodos y objetivos como actividad de control de forma simétrica evolucionó para poder atender y dar respuestas a las nuevas 
exigencias de los clientes a partir del siglo XX, como ya en su momento el catedrático ViCENT CHULIA lo señalaba.

Las EFS (1995), la concibe como una herramienta de gestión ambiental, aunque otros estudios desde las ciencias contables consideren que su génesis está vinculada a la contabilidad y a la auditoría social para dar respuesta a problemas generados al ambiente con la contaminación atmosférica, por el vertido, la lumínica, la sonora, la protección a la biodiversidad, el cambio climático, a los recursos hídricos, al incremento de los niveles de radiación, a la lluvia ácida, por el incremento de las concentraciones de ozono generado por la industria, la mala calidad del aire en las ciudades, el uso y manejo de la tierra, la desertificación, el comercio y el ambiente. Cuestión aún por esclarecerse. Puntualizan que permite en su ejecución por el auditor realizar la evaluación sistemática, documentada, periódica y objetiva de la efectividad de la organización auditada en la gerencia para proteger el bien jurídico público ambiente con un mejor control de las prácticas ambientales y la evaluación para cumplir la política ambiental de la empresa y las normas legales a partir de la institucionalización de la tutela ambiental (ELSTEIN, 2012, pp.17-45).

La norma técnica ambiental ISO 14 001:1995, la define como “...proceso sistemático, autónomo y documentado para obtener evidencias de la auditoría, evalúa de manera objetiva con el fin de determinar la extensión en que se cumplen los criterios de auditoría...".

En la propia década de los 90' del siglo XX, empiezan a publicarse estudios desde las ciencias jurídicas, reflejan el análisis de la política pública ambiental con la integración en su aplicación de herramientas de gestión para determinar los niveles de contaminación, exigir la responsabilidad ambiental, la evaluación ambiental estratégica, la cuantificación del daño ambiental, los servicios públicos ambientales, la inspección ambiental, los permisos ambientales, el uso de las tecnologías limpias, los sistemas de gestión ambiental y la obtención de la certificación ambiental, y el uso de la ecoetiqueta vinculados a la praxis de la auditoría ambiental (SANZ RUBIALES, 2000, pp. 7-19).

Desde el plano jurídico, se analizan los aportes de MARTín MATEO (1991, pp. 145148), Nogueira López (1997, pp. 5-200), LOPERENA Rota (2000, p. 101), ESTEVE PARDO (2002, pp. 21-22), EMBID IRUJO (2015, pp. 3492-3498), señalan que la auditoría ambiental está articulada a una actividad de control, la misma evalúa al sujeto de gestión de manera voluntaria u obligatoria su relación con el ambiente, es concebida como una fórmula de autorregulación ambiental con efecto público externo, no es un servicio público típico; en su ejecución son aplicadas normas técnicas ambientales (ISO 14 000, 19 011, 26 000) y el Sistema Comunitario de Gestión y Auditoría Medioambientales (EMAS) para el sector industrial en Europa; tiene naturaleza jurídica pública y de fomento ambiental, concebida dentro de la fórmula estimulación-recompensa, con efecto directo y vinculante al auditado, puede ser onerosa o gratuita, y su resultado final es certificatorio de la gestión ambiental del auditado. Como se aprecia, aquí hay otro campo nuevo de acción, el "sector industrial" en la práctica de la auditoría al surgir el EMAS. 
Por consiguiente, se valora que la auditoría ambiental se vincula al Derecho Ambiental con el principio de prevención, precautorio, de quien contamina paga, de responsabilidad, de cooperación, y de legalidad; como instrumento de carácter corrector, mejora el comportamiento ambiental al auditado, es interdisciplinaria y puede tener un carácter punitivo (FERNÁNDEZ DE GATTA SÁNCHEZ, 2004, pp. 27-43; CAFERRATA, 2009, pp. 20-55; ANTÚNEZ SÁNCHEZ, 2015).

Queda claro que la auditoría ambiental responde a las necesidades sociales, por ello en la Cumbre de Johannesburgo en 2002, se pondera su uso a escala global como su paraguas como ya se reseñara. Es la herramienta de gestión susceptible de integrarse por su transversalidad en la realización de las revisiones clásicas establecidas por otras ramas de la economía industrial, integrada a otros tipos de auditorías -legalidad, financiera, cumplimiento, gestión- al revisar en sus programas aspectos vinculados con la protección ambiental con una visión estratégica, aplicando la inteligencia ecológica para ello en pos de alcanzar el desarrollo sostenible, ejecutada de forma voluntaria u obligatoria.

Para el autor del artículo, se demuestra que en la ejecución del control ambiental por la EFS se conjugan la competitividad y la sostenibilidad en un equilibrio adecuado con el ambiente, al ponderar la norma técnica ISO 26000 en pos de alcanzar el desarrollo sostenible como paradigma jurídico. Permite evaluar el compromiso de la gestión ambiental con el ambiente para la empresa y la industria (FERNÁNDEZ DE GATTA SÁNCHEZ, 2004, pp.1-19; SALES DE FREITAS, 2013, pp. 293-309).

La auditoría ambiental, pondera el principio de rendición de cuentas como lo explicitan MONEVA ABADíA et al. (2004, pp. 1-27); al ser un derecho de la sociedad, permite conocer el impacto de las actividades que todo sujeto de gestión económica tiene en su comunidad y con el entorno para actuar de manera sostenible y respetuosa con su entorno, ponderando a criterio de los articulistas el principio de información.

Por la transdisciplinariedad en su ejecución, se valora que constituye un reto al exigir la responsabilidad a los actores económicos en la protección al bien jurídico ambiente como bien de uso público, que acate el principio de legalidad, ratificada en la Cumbre de Río en 1992, Johannesburgo 2002, y en la Agenda 2030 en los objetivos del Milenio, donde el control público ambiental es tema recurrente, de aquí que su principal reconocimiento sea en cada país a través del texto constitucional y se desarrolle en los ordenamientos en normas jurídicas especiales, donde de manera indistinta las normas legales la recogen en su ejecución de manera voluntaria $u$ obligatoria.

Aunque queda claro que, la relación empresa-ambiente ha sido conflictiva, los principales daños ambientales los acarrea la empresa y ésta ha percibido la atención al ambiente como un obstáculo en sus actividades y un freno para su desarrollo y para la creación de empleos verdes. Han sido los principales factores que ha obligado a la empresa como sujeto económico, a replantearse su actitud estratégica hacia el ambiente, ante la creciente preocupación social a raíz de la magnitud de la crisis ambiental global, como fruto de la actividad económica insostenible, que impide 
alcanzar los Objetivos del Milenio para el 2030, donde el control público ambiental es pertinente.

Prosiguiendo el análisis, se aprecia como la auditoría ambiental, se le conoce con varios nombres en la literatura científica "ecoauditoría", "revisión ambiental", "control ambiental", "evaluación ambiental", y "vigilancia ambiental", aunque su significado resulta ser el mismo por quien la ejecute y para quien se le notifiquen sus resultados.

Dentro de la familia de los instrumentos de comando y control en la materia ambiental, se valora como los ordenamientos jurídicos, por su origen idiomático, su cultura y su realidad económico-social, consideran que es capaz de evaluar y sentar las bases de una política ambiental dirigida a los empresarios para mitigar la contaminación ambiental. Se vincula a los conceptos de economía y contabilidad ambiental creados por el Programa de las Naciones Unidas para el Medio Ambiente (PNUMA, 2005).

$\mathrm{Su}$ naturaleza jurídica está concebida a partir de que el control es un sistema de verificación y corrección de la legalidad que evalúa el principio de juridicidad, directamente vinculado al concepto de Estado de Derecho, y se relaciona con la democracia como forma política de gobierno nacional. En el marco de un Estado de Derecho, el control implica que la Administración Pública en su organización, funcionamiento, relaciones con la comunidad y su personal están subordinados al ordenamiento jurídico como sujeto pasivo, el que deriva directamente de un marco constitucional. Las normas jurídicas deben someterse a la Constitución Política, y a éstas deberán someterse a su vez, las normas que se derivan de la potestad reglamentaria como lo señala el Derecho Administrativo.

Hay que ponderar en este estudio, que, para la ejecución por el equipo auditoría, la auditoría ambiental, ni las normas, ni el referente doctrinal son homogéneos en lo concerniente a los indicadores a medir, en la significación de los mismos, ni cómo hacerlo atendiendo a las diferencias del desarrollo tecnológico y las formas de gestión económicas auditadas en cada escenario. Los ordenamientos jurídicos no han tenido en cuenta los diferentes momentos de control "no solo a la tecnología existente sino a la que se va adquirir" como mecanismo de prevención para mitigar la contaminación ambiental.

Lleva a justipreciar que, dentro del proceso de la auditoría ambiental, es pertinente evaluar la "economía circular", vinculada a los recursos naturales limitados y a la creciente contaminación creada por la generación de residuos para implementar medidas para que estos productos no sean desechados, sino reutilizados o reciclados para crear nuevos productos por las empresas e industrias con los objetivos del Milenio para el 2030 -objetivo 12: producción y consumo sostenible-.

El que concluye como cierre a criterio del autor del artículo, con el análisis de ciclo de vida (ACV) "Life Cycle Assessment", conocido como análisis de la cuna a la tumba, balance ambiental, balance ecológico o evaluación del ciclo de vida (ECV). Se aprecia que esta evaluación está concebida como una herramienta de diseño que investiga y evalúa los impactos ambientales de un producto o servicio durante todas 
las etapas de su existencia: extracción, producción, distribución, uso y fin de vida (reutilización, reciclaje, valorización y eliminación/disposición de los residuos/desecho), (OWENS, 1996-1998; SAOUTER y FEIJTEL, 2000).

\section{LA AUDITORÍA AMBIENTAL, CAMPOS DE APLICACIÓN EN LA PROTECCIÓN DEL AMBIENTE}

La evolución de la auditoría ambiental en el siglo XXI, acontece en el primer decenio, transita hacia la "auditoría de gestión cooperada" ejecutada en la región de la Amazonía por las EFS en América Latina a los "recursos hídricos, a la "biodiversidad" y al cambio climático", a través de acciones evaluadoras de las políticas públicas y al marco regulatorio ambiental como un nuevo campo de acción. Se aprecia como muta del control clásico del sistema empresarial hacia el ambiente con un nuevo campo de acción. Su régimen jurídico utiliza instituciones jurídicas del Derecho Administrativo como la autorización, la concesión administrativa y el dominio público, todas evalúan el principio de juricidad a través de la gestión ambiental compartida (ELSTEIN, 2012, p. 15; LUSTOSA DA COSTA, 2014, pp. 43-46).

Esta auditoría de gestión ambiental se valora que responde a objetivos económicos, de utilidad, factibilidad, eficacia, reducción de costos, ganancias; los sociales, crecimiento cualitativo y cuantitativo, competitividad, pleno empleo, reducción de riesgos para la vida; y los ecológicos, se dirigen a la utilización económica de los recursos y al mantenimiento del equilibrio y protección ambiental, vinculados al Derecho Administrativo Ambiental, es más completa en su programa que la auditoría ambiental en sí.

En la auditoría de gestión ambiental, se justiprecia que de acuerdo con la perspectiva de las normas técnicas ambientales ISO, mantienen los principios básicos de la auditoría y los de la contabilidad, pero requiere de un auditor que maneje los aspectos específicos de la gestión ambiental en el sujeto económico a auditar, de aquí que en su ejecución se aprecia como pervive la transdisciplinariedad en la conformación del grupo de auditores habilitados. Por ello se valora que es superior a la auditoría ambiental tradicional realizada, este es otro cambio en su tracto evolutivo hacia un nuevo campo de acción como ya fue citado.

En sus estudios, ANTÚNEZ SÁNCHEZ (2019) concibe que la auditoría ambiental, como actividad de control es un instrumento de gestión ambiental de naturaleza jurídica pública, su campo de acción son la empresa, la industria, el ambiente (personas jurídicas y naturales) dentro de la formula estimulación-recompensa, su ejecución es realizada por funcionarios públicos requeridos de título profesional y título habilitante, registrados en el Registro de Auditores y Contralores; su función es evaluadora y certificadora de las metas ambientales en relación con la política ambiental trazada por la organización empresarial, es una técnica de comprobación de la legalidad con una potestad reglada de la Administración Pública. Es un proceso, en su práctica se utilizan procedimientos y metodologías, en ella se evalúa la ejecución gasto contable del patrimonio destinado a la protección ambiental, puede ser ejecutada 
de forma interna o externa, se evalúa la eficiencia del sistema de gestión ambiental en relación con el vertido, la introducción de tecnologías limpias en la organización empresarial, se aplican normas técnicas, se exige la responsabilidad administrativa contravencional, laboral-funcionarial, social-empresarial, civil y penal a los sujetos auditados. Tiene efecto directo y vinculante al auditado, puede ser onerosa o gratuita. $\mathrm{Su}$ resultado final certificatorio le aporta valores añadidos que inciden de forma positiva en el comercio y el mercado a la persona jurídica o natural objeto de la auditoría.

Evidencian estos elementos estudiados hasta aquí, permiten valorar que a pesar de la vasta teorización sobre la auditoría ambiental, aún su construcción conceptual, su regulación y práctica adolece del enfoque sistémico para el logro de la empresa responsable con el ambiente, está necesitada de integración de contenidos entre las diferentes ciencias y saberes para este propósito; hoy con la aparición dentro de la $4^{\text {ta }}$ Revolución Industrial de la Industria 4.0, y los posturas internacionales sobre la Agenda para el desarrollo sostenible 2030, están necesitadas del acompañamiento desde una visión estratégica por los empresarios esta institución jurídica sigue en evolución y desarrollo en los ordenamientos jurídicos que la reconocen, este es el segundo momento evolutivo del control público en la web 2.0, donde se le seguirán incorporando nuevos elementos dentro de su caracterización en la medida que se siga perfeccionando.

Desde el plano jurídico, la evolución en el siglo XXI de la auditoría ambiental con el uso de las Tic en la web 2.0, implementa herramientas digitales en este sentido. Se valora que tiene nexo con las herramientas informáticas al ser utilizadas en la contabilidad, en el comercio electrónico, el uso de la firma electrónica, con la ventanilla única de certificación ambiental dentro del gobierno digital, al ponderar el principio de información, entre otras. La auditoría ambiental, es útil compararla con la auditoría financiera, como su antecedente próximo inmediato dentro de las ciencias contables al estar vinculadas con el análisis contable-financiero a los actores económicos.

Ambas auditorías, la ambiental y la financiera, deben ser conducidas por auditores calificados según los niveles de acreditación, basados mayormente en la experiencia profesional, y en cierto grado, en el entrenamiento y calificación profesional de acuerdo a procedimientos sistemáticos, abarcan un examen o revisión de la actividad para verificar que los aspectos bajo su consideración se ajustan al ordenamiento especificado o planificado dentro del control a ejecutar, por un nexo empresaambiente.

Presentado este panorama científico de la institución jurídica estudiada, luego de analizadas las posturas interdisciplinarias desde las ciencias sociales, la contabilidad, el derecho, las ciencias empresariales, las ciencias informáticas y las ciencias ambientales, evidencian el tratamiento jurídico, contable, ecológico y empresarial que ha tenido esta actividad de control público desde su reconocimiento legislativo en los ordenamientos jurídicos, ejecutada en una evaluación contable ambiental de los estados financieros de la industria y la empresa que la implementa, su naturaleza 
jurídica es evaluadora de la gestión ambiental al sujeto de gestión que la pondera para ser competitivo en el mercado.

\section{LA AUDITORÍA AMBIENTAL APLICADA COMO EVALUADORA A LAS FUENTES RENOVABLES DE ENERGÍA}

Otro problema ambiental que acontece en el mundo, debido a que los combustibles fósiles son recursos finitos y que su quema de ha sido identificada como el motivo principal del fenómeno adverso del calentamiento global, generando el cambio climático. Por ello, en la actualidad las fuentes renovables de energías empiezan a tomar relevancia en el mundo actual, siendo otro "campo de acción de la auditoría ambiental".

Ante la diversidad de la oferta de energías, como una de las condiciones de desarrollo para la región, para que este desarrollo ocurra en bases sostenibles, es imprescindible que tenga matrices energéticas diversificadas. De aquí que las fuentes renovables de energía son aquellas energías que se obtienen de los recursos naturales, su característica principal es su capacidad de ser inagotable tanto por la cantidad de energía que contienen, como por la posibilidad de regenerarse por medio naturales, al no ser contaminantes al ambiente.

Desde el Derecho Ambiental Internacional en el año 2012, se proclama como el "Año Internacional de la Energía Sostenible para Todos", el PNUMA publica un informe en el que pidió a los gobiernos que desarrollaran políticas que fomentaran el uso de las energías renovables en naciones del Tercer mundo. En la región de América Latina y el Caribe, del cual la nación cubana es parte, hay un gran potencial de fuentes renovables de energías, sobre todo en la eólica, la fotovoltaica, la biomasa, el biogás, las olas, y la energía geotérmica. Nos apoyamos en este estudio, del informe publicado por la Comisión Económica para América Latina y el Caribe (CEPAL) "Fuentes Renovables de Energía en América Latina y el Caribe: Situación y propuestas de políticas" (2004).

En su desarrollo, en el siglo XXI, la catedrática MORA RUIZ (2010, p. 1-4), es de la posición al analizar el uso sobre la energía, el desarrollo y el medio ambiente; en la actualidad, los tres vértices de una ordenación jurídica de las energías renovables que precisa de una intervención cualificada del Derecho Administrativo, en la que la satisfacción del interés general implica el equilibrio de estos tres elementos para conseguir los objetivos de seguridad en el abastecimiento de la energía, continuidad en el desarrollo económico de los Estados y tutela del bien jurídico medio ambiente, habida cuenta de que las energías renovables se conceptualizan, casi de manera unánime por la doctrina, como "aquellas fuentes primarias de energía que, de forma periódica, se renuevan a través de ciclos naturales, por lo que se pueden considera inagotables". Desde esta perspectiva, la efectiva ordenación de las energías renovables es determinante para la consecución de estos objetivos que, aunque dispares en apariencia, se encuentran íntimamente relacionados. 
La autora estudiada precisa de autores que en su momento, por la importancia del tema como nuevo campo de acción de la auditoría ambiental "las energías renovables", acotaba con precedencia que, el académico MARTIN MATEO (1982, p. 146) disertaba sobre un nuevo Derecho Energético, con bastante antelación, en las medidas de ahorro energético, como vía de equilibrio del crecimiento económico ante el aumento de demanda de energía, de forma que "...el ahorro energético pasa a constituir la denominada "fuente invisible de energía», sin que ello suponga necesariamente la disminución del ritmo de desarrollo, ni la limitación de satisfacciones...". Aunque los articulistas también, han constatado otra denominación por la que se le conoce "Derecho de la Energía", que ambos su objeto de estudio es el mismo, pero tuvo una visión que hoy en el siglo XXI es que se fomenta su uso al ser menos contaminadora.

Prosigue otra mirada al análisis ejecutado por el profesor GARCÍA Novo (2007, pp. 231-232), quien señala "...que el acceso a la energía...adquiere en el tercer milenio la condición de supervivencia de la sociedad y biosfera...", de forma que, en nuestra opinión, la relevancia de las fuentes de energía renovables trasciende del mero auxilio en la lucha contra el cambio climático, adquiriendo una dimensión global fundamental.

Coincidimos con la posición de la catedrática MORA RuIz (2010, pp. 1-10) para quien señala que insistir en la importancia de la ordenación de las energías renovables, conectada a las valoraciones que hace sobre la necesaria relación entre energía, medio ambiente y sostenibilidad, y a poner de manifiesto la necesidad de contar con un marco jurídico adecuado y, sobre todo, eficaz, no sólo desde la perspectiva puramente ambiental, sino también, desde un enfoque económico asociado a la relevancia del sector energético como ámbito de desarrollo económico.

Desde esta perspectiva jurídica, lo ambiental se incorpora decididamente en el diseño de estas políticas públicas, pero precisa de una ordenación jurídica acertada que, por un lado, haga atractiva a los inversores la producción de energía a partir de fuentes renovables y, de otro, no convierta las exigencias de sostenibilidad en un elemento de distorsión en los mercados energéticos, con el consiguiente riesgo de no avanzar en la generalización de estas energías como una subrama del Derecho Ambiental para su estudio y desarrollo.

Ejemplos de lo estudiado, son apreciados en la actividad de fomento que se estudia desde el Derecho Administrativo Ambiental, con la creación de parques eólicos como fuente de energía renovable vinculados a la generación de electricidad en el sector eléctrico al utilizar la energía que proporciona el viento. Otro ejemplo es la creación de parques fotovoltaicos, los que utilizan la energía que genera el Sol, y estos la convierten en electricidad, administrada por el sector público, y la energía generada por las olas de los mares. Tienen a criterio de los articulistas un denominador común, el uso de tecnologías para obtener esta energía.

La actividad de fomento desde el Derecho Público, se percibe que está dirigida a los empresarios, para que desarrollen e implementen en sus empresas e industrias el uso de energía no renovables a través de calentadores, paneles solares, generadores de 
biogás, motores eólicos, y cualquier otra tecnología o producto que use como fuente total o parcial las energías no convencionales, acorde a la norma legal del sector eléctrico, la legislación ambiental, la legislación del uso de las energías no renovables no convencionales, legislación sobre incentivos fiscales para el fomento de las energías no renovables, la exención de impuesto dirigidos a la construcción de maquinarias, autos, ciclomotores, entre otras, en los ordenamientos jurídicos de las naciones en América Latina como Nicaragua, Chile, el Salvador, Argentina, Brasil, República Dominicana, y Costa Rica, entre otras naciones incorporadas al uso de la energía verde, como lo han ponderado VALLS (1977) y DRNAS DE CLÉMENT (2016) desde sus estudios en la materia ambientalista y en particular del Derecho de la Energía como nuevo paradigma dentro de las políticas públicas en relación con el uso de la energía verde y el Derecho Ambiental en la preservación del ambiente como derecho humano con puntos de encuentro.

El autor del artículo, también observa que el fomento de esta actividad precisará de desarrollar programas de capacitación y formación de los recursos humanos en todos los campos de aplicación de las energías renovables para su uso, implementación y regulación en el ordenamiento jurídico, así como en cuestiones de índole jurídico en la materia tributaria, como nuevo campo de acción de la auditoría ambiental desde el Derecho Administrativo Ambiental.

\subsection{Las energías renovables, su uso, implementación y regulación en el ordenamiento jurídico cubano a partir del control público ambiental}

En relación al tratamiento de las energías renovables, se aprecia su expresión en el cumplimiento de los Objetivos del Milenio para el 2030 en la nación cubana, en el ordenamiento jurídico promulgado desde el pasado siglo XX en el año 1975, se aprueba la Ley No. 1287, Ley Eléctrica Cubana, sus objetivos plasman garantizar la ordenación y regulación del crecimiento de la industria eléctrica, para hacer frente a la creciente demanda en función del desarrollo económico y social del país.

En el propio 1975, fue aprobado y publicado el Reglamento del Servicio Eléctrico, estableciéndose las bases regulativas para la utilización racional y aprovechar al máximo la energía eléctrica, siendo necesaria la actualización y unificación de las normas técnicas reguladoras de la materia. Este cuerpo jurídico, faculta al Ministerio de la Industria Eléctrica como suministrador único de este servicio en la nación, y dispone las prioridades establecidas por el Gobierno para el desarrollo de los planes económicos y sociales creado en 1976.

Un acontecimiento importante en el adelanto de las fuentes renovables fue la creación y puesta en funcionamiento del Centro de Investigaciones de Energía Solar en la ciudad de Santiago de Cuba entre 1980-1984 en la nación cubana. En el año 1984, se promueve la creación de diferentes Grupos de Desarrollo e Investigación en los Órganos de la Administración Central del Estado y en casi todas las provincias, dedicados a la generalización del uso de diferentes fuentes renovables de energía, principalmente la hidráulica, el biogás, la biomasa, la solar térmica y la eólica. 
En esta década estudiada en el orden económico, en la isla de Turiguanó se implementan los primeros generadores de energía eólica en el país, cuestión que se ha ido expandiendo a otras regiones como en la provincia de Las Tunas en la zona de la Herradura. En materia de energía fotovoltaica hay ejemplos en las regiones de Pinar del Rio, Ciego de Ávila, Granma y Cienfuegos de su implementación. De la ejecución de pequeñas hidroeléctricas en ríos cubanos, las pequeñas bioeléctricas en los centrales azucareros, como es el caso de la provincia de Ciego de Ávila.

En la década de los 90', la Asamblea Nacional del Poder Popular aprobó el Programa de Desarrollo de las Fuentes Nacionales de Energía, sus objetivos se dirigían sobre la base de lograr mayor eficiencia en el uso del bagazo y los residuos agrícolas cañeros (biomasa); extender la utilización de las energías hidráulica, solar térmica, solar fotovoltaica y eólica, así como el biogás y los desechos industriales, agrícolas y urbanos.

En esta propia década analizada de los 90', en la sociedad civil se funda la Sociedad Cubana para la promoción de las fuentes renovables de energías y el respeto ambiental (CUBASOLAR), por la Academia de Ciencias de Cuba y la Comisión Nacional de Energía, con el organismo de referencia el Ministerio de Ciencia, Tecnología y Medio Ambiente (CITMA).

En el orden político, en el 2011 se aprueban los Lineamientos de la Política Económica y Social del Partido y la Revolución para la actualización del modelo económico y social en Cuba. Este documento definió el sistema económico que prevalecería desde ese año, basándose en los mismos principios de la propiedad socialista vigentes hasta el momento, teniendo en cuenta las tendencias del mercado. Dentro de estos, se encuentra identificada la política energética del país y las medidas a adoptar para actualizarla, por lo que a raíz de este, se buscó la adopción de métodos y técnicas eficaces de sistemas de energía menos contaminantes y más eficientes; el aumento del uso de fuentes de energía nuevas, renovables y económicamente viables, para reducir los efectos nocivos sobre la atmósfera y el medio ambiente; el incremento de la producción, distribución y utilización de la energía en forma eficiente, segura y ecológicamente racional; y la promoción de la cooperación internacional para el Desarrollo del Programa Energético Nacional.

En el orden legislativo, a raíz de las transformaciones de la nación cubana, en el ordenamiento jurídico aparece el Decreto Ley No 301 de 2012, donde se crea el Ministerio de Energía y Minas, como evolución del antiguo Ministerio de la Industria Básica. Desde el plano jurídico, vinculantes dentro del propio ordenamiento jurídico con el tema analizado en el artículo, se aprecian los cuerpos legales siguientes vinculantes al tema objeto de estudio, con la Ley No. 81 de 1997, Ley del Medio Ambiente, la Ley No 118 de 2014, la Ley de la Inversión Extranjera, y el DecretoLey No 165 de 1996, De las Zonas Francas y Parques Industriales, y el Decreto Ley No. 313 de 2013, Zona Especial de Desarrollo del Mariel, y la Ley No. 124 de 2014, Ley de Aguas Terrestres.

Ahora bien, se valora que, para propiciar el uso de las fuentes de energías renovables o energía verde, no solo se deberán realizar acciones en el ámbito de las 
investigaciones, la innovación e inversión extranjera. Hace falta, un componente legal que ofrezca la seguridad jurídica para el estímulo de proyectos futuros, y es ahí donde el Derecho, como ciencia reguladora de las relaciones sociales, es una herramienta útil en este sentido, la actividad de control analizada.

Se justiprecia por los articulistas que, la Ley No 1287 de 1975, Ley Eléctrica cubana y su Reglamento, es el momento de su actualización por el legislador, con el fin de que responda y se atempere a la realidad actual del siglo XXI en la materia energética con la actualización del modelo económico y social. Hay que significar que esta norma jurídica citada, con sus 45 años de vigencia, en un periodo de abundancia en combustibles fósiles por ser la nación cubana parte del bloque económico de los países socialistas, Consejo de Ayuda Mutua Económica (CAME), regula las primeras medidas para evitar el despilfarro o inadecuado aprovechamiento de la energía, reconociéndose como objetivo obligado, establece la necesidad de actualizar y unificar las diversas normas técnicas en la materia, dispersas hasta ese momento de su emisión. Elementos que se consideran válidos para la actualización del Derecho Administrativo sancionador.

A partir de la promulgación del nuevo texto constitucional de 2019, se considera que los retos del legislador cubano, son actualizar la Ley No 1287 de 1975, Ley Eléctrica y la Ley No. 81 de Medio Ambiente de 1997, que se valore la aprobación de nuevas normas jurídicas con rango de Ley sobre Economía Sostenible, de Eficiencia Energética y Energías Renovables, y sobre Energías para que permita armonizar la diversidad energética que pervive en la nación cubana, con estas regulaciones se podrá incidir en lograr un mayor aporte de las energías renovables a la generación eléctrica, creará mayor independencia a la importación de combustibles, estimulará como política pública que tribute al fomento en la presentación y ejecución de proyectos inversionistas a partir del uso de las energías renovables.

Claro está, se apercibe aquí deberá jugar un papel determinante la política fiscal establecida en la Ley No 113 de 2012, Ley Tributaria, contempla otorgar beneficios fiscales, préstamos preferenciales con bonificación de intereses financieros, exención de impuestos de importación, y el pago de una retribución a las instalaciones de energía renovables generadores de electricidad vinculados al uso de estas, como parte de esta política antes citada por la Administración Pública.

Hay que destacar, que, en la actualización del ordenamiento jurídico, el Decreto Ley No. 345 de 2019, Del desarrollo de las fuentes renovables y el uso eficiente de la energía, ha dispuesto novedades jurídicas en materia de producción de energía por productores independientes que no son parte de la Unión Nacional Eléctrica, a la cual esta se la puede comprar, es el ejemplo de la energía que se produce en la Agroindustria del Azúcar con los desechos de la caña, con su fundamento legal esencial en el artículo 75 constitucional. Se dispone un Programa Nacional de desarrollo para las personas jurídicas para el fomente de energías verdes eficientes por la Administración Pública. En el orden fiscal promueve incentivos arancelarios y fiscales, y créditos bancarios. 
Hay que significar que por vez primera el sector privado se le autoriza adquirir estas tecnologías y vender su excedente al sector público como ya se reseñó en esta nueva norma jurídica aprobada. Aquí se prioriza la inversión extranjera, al ser la misma la que introducirá tecnología de punta a la nación. Disposición normativa que se acompaña con actos administrativos internos de Ministerios de Energía y Minas, de Comercio Exterior, la Banca Central de Cuba, y por el Ministerio de Finanzas y Precios.

Permite analizar y valorar que la auditoría coordinada sobre energías renovables se realizó en el 2018-2019 en los países de Brasil, Chile, Colombia, Costa Rica, Cuba, Ecuador, El Salvador, Guatemala, Honduras, México, Paraguay, y Venezuela en alianza entre el Tribunal de Cuentas de la UNION (TCU) y la Organización Latinoamericana de Entidades Fiscalizadoras Superiores (OLACEFS). El objetivo de la actividad de control fue evaluar las políticas públicas para la expansión de las fuentes renovables en la matriz eléctrica, en particular, mediante la identificación de buenas prácticas y oportunidades de mejora en estas políticas, a fin de contribuir al cumplimiento de los compromisos adquiridos a través de los Objetivos de Desarrollo Sostenible (2030) y el Acuerdo de París.

En relación a la situación de la nación cubana, se señalan como deficiencias en el resultado de esta evaluación realizada en atención a datos desactualizados sobre emisiones de Gases de Efecto Invernadero, lo que dificulta el seguimiento de posibles avances en relación con las reducciones; problemas en el seguimiento de metas o directrices por la ausencia de monitoreo adecuado o por deficiencias en los indicadores establecidos; debilidades en la articulación entre los actores responsables de las políticas de inserción de fuentes renovables en la matriz energética; falta de evaluación de los resultados de los incentivos otorgados a las fuentes renovables, lo que genera un riesgo de que las estrategias adoptadas no se justifiquen en términos de costo-beneficio; debilidades de los instrumentos gubernamentales para asegurar que la expansión de las fuentes renovables se realice para garantizar la confiabilidad y la economía del sistema eléctrico.

En fin, esta actividad de control realizada a partir del 2014 ha permitido, la acción conjunta de los países miembros de Organización Latinoamericana de Entidades Fiscalizadoras Superiores (OLACEFS) puede servir de ejemplo para la ejecución de auditorías coordinadas por otras EFS, ya que mitigar los efectos del cambio climático es un problema transnacional que requiere el esfuerzo conjunto de la comunidad internacional.

Son estos elementos estudiados, los que conllevan a considerar que este programa de auditoría ambiental a la energía verde, deberá estar centrado por su transdisciplinariedad y multidisciplinariedad a evaluar el cumplimiento de los componentes desde el Derecho Administrativo Ambiental al integrarse contenidos en su proceso de evaluación, en:

- La legislación en materia ambiental vinculada a las energías renovables en relación a su uso sostenible 
- La documentación legal de la entidad a cargo de la gestión de la energía renovable en el expediente legal

- La evaluación de los asientos contables vinculados a la protección ambiental registrados en el patrimonio como sujeto de gestión

- La evaluación de los activos fijos contables asentados en su patrimonio vinculados a la protección ambiental

- Grado de cumplimiento de la gestión ambiental del sujeto de gestión auditado

- Grado de cumplimiento de la política ambiental estatal para la protección ambiental

- Cumplimiento de los Objetivos 2030 para el desarrollo sostenible de la forma de gestión auditada

- Formación de los recursos humanos en la materia ambiental en relación con el capital financiero destinado a ello

- Acciones de control ejecutadas a la empresa donde se evalué la gestión ambiental y se conozcan sus avances y retrocesos

- Plan de sustitución de la tecnología que incida en las producciones limpias en la gestión ambiental empresarial

- Ponderación del uso de la etiqueta ambiental en la producción empresarial por los sujetos económicos

- Cumplimiento de las normas técnicas ambientales en la actividad empresarial por los sujetos económicos

- Actualizar la norma jurídica de la auditoría en el ordenamiento jurídico cubano, que permita ejecutar la auditoría ambiental a las personas naturales, como aparece en el texto jurídico, el sector privado que no ejerce como empresario privado como propuesta de la Contraloría General en Cuba

- La evaluación de las licencias ambientales autorizando el uso de la energía verde por el CITMA

- La evaluación del impacto ambiental del ciclo de vida dentro de la gestión ambiental a los sujetos económicos por el CITMA.

Presentado este panorama científico de la institución jurídica estudiada en el desarrollo del artículo, con el análisis de posturas interdisciplinarias desde las ciencias sociales, la contabilidad, el derecho, las ciencias empresariales, las ciencias informáticas y las ciencias ambientales, evidencian el tratamiento jurídico, contable, ecológico y empresarial que ha tenido esta actividad de control público desde su reconocimiento legislativo en los ordenamientos jurídicos, ejecutada en una evaluación contable ambiental de los estados financieros de la industria y la empresa que la implementa, su naturaleza jurídica es evaluadora de la gestión ambiental al sujeto de gestión que la pondera para ser competitivo desde los diversos campos de acción donde ha transitado, la cual sigue en evolución en el siglo XXI en pos del desarrollo sostenible desde la economía circular.

\section{CONCLUSIONES}

El origen de lo que hoy se conoce desde la "teoría del control", se ha comprobado que la auditoría como actividad de control tiene su génesis desde las antiguas culturas. 
Tuvo su mayor desarrollo en el continente europeo, lo que permitió e incidió en su irradiación como paraguas al resto de los continentes, desarrollándose en la medida del desarrollo industrial de cada país.

La preocupación ambiental y ética de las empresas como sujetos de gestión de acuerdo con las tendencias de las sociedades no son nuevas, toma auge desde la década de los 90' del siglo XX a escala global; en el siglo XXI la protección del bien jurídico ambiente se exterioriza en tres dimensiones: la económica, la social y la ambiental a partir del desarrollo industrial, equilibrado para generar recursos, empleos y promover la educación ambiental como bases del bienestar social y la calidad de vida, para lograr el principio del desarrollo sostenible con la aplicación de la Responsabilidad Social Empresarial al conformarse la Empresa Responsable con el Ambiente y tributar al alcance del desarrollo sostenible como su campo de acción.

En América Latina, la ecoauditoría se mueve en su desarrollo con tres auditorías ambientales las que centran su campo de acción al ambiente, permitió a la Administración Pública obtener información del comportamiento de las políticas públicas y de la normativa ambiental como paradigmas ambientales, trazar estrategias que involucran a todos los actores que intervienen en la protección ambiental, desarrollar nuevas tácticas, recomendaciones, campañas de fomento de la cultura ambiental para alcanzar el desarrollo sostenible, distinguiéndola de los modelos de los Estados Unidos de América y el de la Comunidad Europea, al reconocerse como sujeto a la naturaleza dentro del Pluralismo Jurídico De Jure.

En Cuba, la auditoría ambiental a la energía verde emerge en el 2019, ejecutada por la Contraloría General de la República como actividad de control al amparo de la Ley No. 107 de 2009. En relación al Derecho de la Energía no hay una construcción teórico doctrinal que permita su estudio, donde se incorporen elementos estructurales del Derecho Ambiental como nueva disciplina autónoma del derecho desde las ciencias sociales. Su antecedente fue en el 2014, con la ejecución de la auditoría ambiental a la Cuenca Hidrográfica Vento Almendares en el enfrentamiento al cambio climático.

En el ordenamiento jurídico cubano, con la promulgación del Decreto Ley No. 345 de 2017, se permite el fomento del uso de la energía verde por las personas naturales y el sector estatal como actor que presta este servicio público, es una vía de dar respuesta a los efectos adversos del bloqueo impuesto por los Estados Unidos de Norteamérica que impide el adquirir petróleo para la generación eléctrica. Establece que la tutela del servicio eléctrico le corresponde al Ministerio de Energía y Minas, pero reconoce a la persona natural en la generación de energía, liberando esta actividad. El reto es que como se contextualizará su adquisición en el mercado foráneo y el nacional dentro de las estrategias de la política pública nacional para la mitigación de la crisis energética en la relación ambiente-desarrollo de la economía y la energía dentro del modelo cubano con su actualización en el ámbito económico y social.

El Derecho Administrativo Ambiental a través de la actividad de control ejecutada por el Ministerio de Ciencias, Tecnología y Medio Ambiente al amparo de la Ley No. 81 de 1997, le corresponderá observar el cumplimiento de principios que informan como el de prevención, precaución, no regresión, legalidad, en pos de las exigencias 
de la tutela ambiental en la protección ambiental con el fomento de la energía verde que permita conocer los resultados del modelo implementado en relación con la investigación, el desarrollo, y la innovación en el sector público y el privado atendiendo a su clasificación jurídica considerados res communis omnium, como integrantes del dominio público y los del dominio privado.

La academia cubana a través de la carrera de Derecho, como ciencia social, tiene el reto de profundizar los estudios del Derecho Ambiental energético, y en otras ciencias por la transdisciplinariedad del tema ante los retos de la crisis económica en la formación del pregrado y posgrado en el sector público y el privado, a tenor de los cambios del modelo económico y social tras la actualización del texto constitucional en el 2019 desde la perspectiva académica con la integración de contenidos.

\section{BIBLIOGRAFÍA}

AA.VV. (2004). Temas de Derecho Administrativo cubano, $1^{\text {a }}$ edición, Editorial Félix Varela, La Habana.

AA.VV. (2007). Derecho Ambiental cubano, 2ª edición, Editorial Félix Varela, La Habana.

AA.VV. (2010). Lecciones de Derecho Administrativo Ambiental, Universidad Pablo de Olavide, España.

AGENDA (2030). Los Objetivos de Desarrollo Sostenible (2018) Una oportunidad para América Latina y el Caribe, CEPAL.

ANTÚNEZ SÁNCHEZ, A. (2015). Los principios del Derecho Ambiental que informan la auditoría ambiental en su aplicación por la Entidad Fiscalizadora Superior en Cuba, Revista De Jure, México.

ANTÚNEZ SÁNCHEZ, A. (2018). La fórmula estimulación/recompensa en el Derecho Administrativo Ambiental. Visión desde la administración estratégica por los sujetos de gestión, Revista de investigación y análisis De Jure No. 91, México.

ANTÚNEZ SÁNCHEZ, A. y POLO MACEIRAS, E. (2015). El tratamiento jurídico de la etiqueta-certificación ambiental. Regulación en el Derecho Cubano, Revista Iberoamericana de Derecho Ambiental y los Recursos Naturales No. 18, Argentina.

ANTÚNEZ SÁNCHEZ, A. y RAMÍREZ SÁNCHEZ, A. (2016). La potestad inspectiva v/s auditoría pública. Ojeada histórica dentro del Derecho Administrativo Ambiental cubano, Revista Dos Tribunais Thomsonreuters No. 967, Brasil.

AYES ATMELlER, G. (2006). Desarrollo Sostenible y sus Retos. Colección Divulgación Científica. Editorial Científico-Técnica. La Habana.

ALVARADO RIQUELME, M. (2014). Teoría y práctica de la auditoría, Editorial Pirámide, España.

ARTEAGA SILVA, K. (2015) Tesis de maestría: Ecogestión y Ecoauditoría, un instrumento de protección medio ambiental, Universidad Complutense de Madrid. España.

BARREIRO ZABALA, L. (1922). Los Chartered Accountant. Editorial Artes Gráficas Grijelmo. España. 
BARREIRO, R. (2002). Derecho de la Energía Eléctrica. Editorial Abaco de Rodolfo Depalma, Buenos Aires.

BELLORIO CLABOT, D. (2004). Tratado de Derecho Ambiental, $1^{\mathrm{a}}$ edición, Editorial Astrea, Buenos Aires.

BETANCOR RODRÍGUEZ, A. et al. (2004). EMAS: análisis, experiencias e implantación, Ecoiuris, España.

BOWEN, H. (1953). La responsabilidad social de los empresarios. La auditoría, vínculos con otras ciencias y saberes, Estados Unidos de América.

BOWEN, H., GOND, J. \& BOWEN, P. (2013). Social Responsibilities of the Businessman. University of Iowa Press. EUA.

BRACAMONTES ALDANA, J. (1994). Marco legal de las auditorías ambientales en el mundo. La protección ambiental con la combinación de legislación, regulación y políticas voluntarias a la industria. UNAM. México.

BOAZ MOSELLE, J. y RICHARD, S. (2011). Electricidad verde: energías renovables y sistema eléctrico. Editorial Marcial Pons, Madrid.

BROSETA PONT, M. (2010). Manual de Derecho Mercantil, Editorial Tecnos, Madrid.

BECKER, F. (2009). Tratado de regulación del sector eléctrico. Aspectos jurídicos. Tomo I, Editorial Thomson Aranzadi, España.

BECKER, F. et al. (2010). Tratado de energías renovables: Aspectos jurídicos, Tomo II, Editorial Aranzadi, Cizur Menor.

CAFERrATA, N. (2009). Teoría de los principios del Derecho Ambiental, Revista Abeledo Perrot, Argentina.

CÁNOVAS GONZÁLEZ, D. (2010). Licencia ambiental y sistemas de responsabilidad, El Derecho Público en Cuba a comienzos del siglo XXI, Editorial de la Universidad de La Habana.

CARABAllo MAQUEIRA, L. (2014). El Derecho Ambiental. Realidades y esperanzas, Editorial Acuario, La Habana.

CALDEIRA BRANT, L. et al. (2016). Desarrollo sostenible y matriz energética en América Latina. La universalización del acceso a la energía limpia, Editorial Konrad-AdenauerStiftung, Brasil.

Conceptualización del modelo económico y social cubano de desarrollo socialista, 7mo Congreso del Partido Comunista de Cuba (2016). Editorial Política, La Habana.

CONESA FERNÁNDEZ-VITORA, V. (2003). Instrumentos de la gestión ambiental en la empresa, $4^{\mathrm{a}}$ edición, Editorial Mundi-Prensa, España.

CUBILlos, A. et al. (2011). Energía y Medio Ambiente. Una ecuación difícil para América Latina, Editorial Universidad Santiago de Chile. Chile.

CITMA (2017). Estrategia Ambiental Nacional 2017/2020. La Habana.

CITMA (2018). Programa Nacional de Educación Ambiental para el Desarrollo Sostenible 2016/2020. La Habana.

CREMADES, J. y RODRÍGUEZ-ARANA, J. (2006). Derecho de la Energía. Editorial La Ley. Madrid. 
CHULIA, F. (2005). Introducción al Derecho Mercantil, $18^{\mathrm{a}}$ edición, Editorial Tirant Lo Blanch, Valencia.

D’ESTÉFANO PISANI, M. (1996). Derecho Ambiental Internacional, Editorial Ciencias Sociales, La Habana.

DÍAZ LEGÓN, O. et al (2016). Apuntes sobre la Ley No. 113, Del Sistema Tributario, en el marco de las transformaciones económicas en Cuba. Estudios Jurídicos, Editorial Loynaz, Pinar del Río.

DI CAGNO, V. et al. (2005). La protección del medio ambiente en Cuba, Editorial Ciencias Sociales, La Habana.

DELGADO DÍAZ, C. (2002). Cuba verde: en busca de un modelo para la sustentabilidad en el siglo XXI, Editorial Félix Varela. La Habana.

DRNAS DE CLÉMENT, Z. (2016). EL Derecho Ambiental y el Derecho de la Energía, $¿$ ¿Paradigmas compatibles o contrapuestos? Argentina.

ESTEVE PARDO, J. (2008). Derecho del medio ambiente, 2a edición, Editorial Marcial Pons, España.

ESTEVE PARDO, J. (2014). Lecciones de Derecho Administrativo. Editorial Marcial Pons, $4^{\mathrm{a}}$ edición, España.

ELSTEIN, S. (2012). La auditoría del medio ambiente crece y evoluciona para afrontar los retos de un ambiente cambiante, Revista de Auditoría Gubernamental INTOSAI. España.

EMBID IRUJO, A. et al (2008). Agua y Energía, Editorial Civitas- Thomson Reuters, España, pp. 249

FERNÁNDEZ RUBIO-LEGRA, Á. (1999). Derecho Ambiental Internacional, Editorial AFR, La Habana.

FERNÁNDEZ-RUBIO LEGRÁ, Á. (1999). Ley No . 81 en más de 150 preguntas y respuestas, Editorial MINJUS, La Habana.

FERNÁNDEZ DE GATTA SÁNCHEZ, D. (2004). Principios del Derecho Ambiental, la responsabilidad social corporativa en materia ambiental, Boletín Económico ICE No. 2824, España.

FERNÁNDEZ DE GATTA SÁNCHEZ, D. (2008). Derecho Ambiental, Editorial Trivium, España.

FERNÁNDEZ DE GATTA SÁNCHEZ, D. (2008). Las auditorías ambientales, Editorial Tirant lo Blanch, España.

FERNEY, M. L. (2003). Intervención del Estado en los negocios jurídicos de energía eléctrica en Regulación Eléctrica: Estudio jurídico. AMIN. Universidad Externado de Colombia, Bogotá.

FRONTI DE GARCÍA, L. et al. (2003). Auditoría ambiental, un nuevo enfoque profesional, Universidad de Buenos Aires, Argentina.

HERNÁNDEZ HERNÁNDEZ, R. (2015). Ley No. 118, Ley de la inversión extranjera (edición revisada y actualizada), Editorial ONBC, La Habana.

HERRERA MOLINA, P. (2000). Derecho Tributario Ambiental. Editorial Marcial Pons, España. 
HERAS, I. et al. (2008). Evolución de la adhesión del EMAS en la Unión Europea y España, Editorial Ambienta, España.

GARCÍA NOVO, F. (2007). Escenario ambiental del modelo energético. Energía y Regulación, Editorial Thomson-Civitas, Cizur Menor, pp. 227-253.

GIRONELLA MASGRAU, E. (1976). El control interno y la censura de cuentas, Editorial ICE. España. p. 15.

GONZÁLEZ GONZÁLEZ, D. (2017). Tesis Maestría: Propuestas para la regulación jurídica de la Cogeneración en Cuba. Universidad Central Marta Abreu de Las Villas.

GONZÁLEZ RÍOS, I. (2011). El régimen jurídico-administrativo de las energías renovables y la eficiencia energética, Editorial Thomson-Aranzadi, Cizur Menor, Navarra.

RAMÍREZ ORTIZ, D. et al. (2014). Derecho Ambiental y desarrollo sustentable, $2^{\mathrm{a}}$ edición, Editorial Porrúa, México.

RAMÍREZ SÁNCHEZ, A, \& ANTÚNEZ SÁNCHEZ, A. (2019). El régimen jurídico de la inspección administrativa en Cuba. Apuntes para una reforma, Revista Derecho \& Paz, No. 38, Brasil.

REY SANTOS, O. et al. (2017). La Ley de medio ambiente: 20 años después, Editorial UNIJURIS, La Habana.

RODRIGO, A. (2015). El desafío del desarrollo sostenible. Los principios del Derecho Internacional relativos al desarrollo sostenible. Editorial Marcial Pons, España.

RODRÍGUEZ-CAMPOS GONZÁLEZ, S. (2003). El fomento de la ecoauditoría como estrategia interventora, Editorial Thomson Civitas, Madrid.

RODRÍGUEZ, T. et al. (2004). Tabloide de energía. Editorial Academia. La Habana.

GONZÁLEZ RÍOS, I. (2011). Régimen Jurídico-administrativo de las energías renovables y de la eficiencia energética. Editorial Aranzadi, Navarra.

MARTÍN MATEO, R. (1982). Nuevo Derecho energético, IAP, España.

MARTÍN MATEO, R. (1991). Tratado de Derecho Ambiental, 3 tomos, $1^{\text {a }}$ edición, Editorial Trivium, España.

MARTÍN MATEO, R. (1997). Derecho Administrativo Ambiental, 6 ${ }^{\text {a }}$ edición, Editorial Trivium, España.

MARTÍN MATEO, R. (2003). Manual de Derecho Ambiental, Editorial Thomson Aranzadi, España.

MORA RUIZ, M. (2010). Los condicionantes ambientales de las energías renovables: el ejemplo de la energía eólica y su regulación en el derecho español. Procedimiento Administrativo: Simplificación administrativa, mejora de la eficacia y garantías de los ciudadanos. Universidad de Navarra, España.

MORA RUIZ, M. (2011). La ordenación jurídico-administrativa de las energías renovables como pieza clave en la lucha contra el cambio climático: ¿un sector en crisis? Universidad de Navarra, España.

MONEVA ABADÍA, J. \& LAMEDA MONTERO, I. (2004). Sostenibilidad vs rentabilidad en las grandes empresas españolas. La contabilidad sin fronteras. Universidad de Granada, España. 
MUÑOZ MACHADO, S. (1998). Servicio público y mercado. Tomo IV. El sistema eléctrico. Editorial Civitas, Madrid.

NIETO, A. (2005). Derecho Administrativo sancionador. $4^{\mathrm{a}}$ edición. Editorial Tecnos, España.

NOGUEIRA LÓPEZ, A. (2010). Hacia un EMAS de alcance internacional en competencia con la ISO 14001: notas a la revisión del Reglamento EMAS, Revista electrónica Actualidad Jurídica Ambiental, España.

PAREJO ALFONSO, L. (2013). Lecciones de Derecho Administrativo, orden económico y sectores de referencia, Editorial Tirand Lo Blanch, España.

PEÑA CHACÓN, M. et al. (2019). Derecho Ambiental del siglo XXI, $1^{\text {a }}$ edición, Editorial Isolma, Costa Rica.

PEÓN, J. (2008). Desarrollo de fuentes renovables en Energía y regulación en Iberoamérica. Tomo I. Editorial Aranzadi, Cizur Menor.

PEREIRA, M. (2016). Hacia la construcción de un Derecho Energético Ambiental como disciplina autónoma. Revista Jurídicas CUC No 16, pp. 181-208.

PÉREZ MORENO, A. (2006). El Derecho de la Energía, IAAP, Sevilla, pp. 455-508.

PICHS MADRUGA, R. (2004). Economía mundial, energía y medio ambiente, Editorial Ciencias Sociales, La Habana.

PNUMA (2005). Auditoría ambiental: evolución histórica y su entorno político institucional. ONU.

ROMANQUE, D. (1996). El Contador y su Rol en la Empresa Ambientalmente Responsable, Revista Ambiente y Desarrollo No 1 , España.

SUAREZ SUARÉZ, A. (1990). La moderna auditoria, análisis conceptual y metodológico. Editorial McGraw-Hill de Management. Madrid.

JAQUENOD DE ZSOGON, S. (1991). El Derecho Ambiental y sus Principios Rectores, Editorial Dykinson, Madrid, p.372.

JAQUENOD DE ZSOGON, S. (2004). Derecho Ambiental, 2a Edición, Editorial Dykinson, Madrid.

JORDANO FRAGA, J. (2008). Un desafío para los ordenamientos en el siglo XXI: el desarrollo sostenible. QDL. Fundación Democracia y Gobierno Local. España.

TARRÉS VIVES, M. (2003). Normas técnicas y ordenamiento jurídico, Editorial Tirant Lo Blanch, Valencia.

TUA PEREDA, J. (2008). Evolución y situación actual del pensamiento contable. La inserción de la contabilidad ambiental en la empresa. Revista Legis de Contabilidad \& Auditoría $\mathrm{N}^{\circ}$ 24. Colombia.

TUA PEREDA, J. (2012). Pacioli la partida doble y el renacimiento, Revista de Contabilidad, España.

JUSTE RUIZ, J. (2009). La evolución del Derecho Internacional del Medio Ambiente, España, pp.467-474.

JUSTE RUIZ, J. \& BOU FRANCH, V. (2017). El desarrollo sostenible tras la cumbre de Río + 20: desafíos globales y regionales. Editorial Tirant lo Blanch. España. 
LOPERENA ROTA, D. (1998). Los principios del Derecho Ambiental. Editorial Civitas. España. p. 87.

LÓPEZ SAKO, M. (2008). Regulación y autorización de los parques eólicos, Editorial Thomson-Civitas, Cizur Menor, España, pp. 160 y ss,

LUSTOSA DA COSTA, C. (2014). Las auditorías coordinadas y sus contribuciones para los Estados Federales: la experiencia de la auditoría en la Amazonía, Revista OLACEFS No. 15. Brasil.

SANZ RUBIALES, I. (2012). El mercado de los derechos a contaminar, Editorial Lex Nova, España.

SALES DE FREITAS, J. (2013). Auditoría externa ambiental como instrumento de defensa del medio ambiente, Revista De Jure $\mathrm{N}^{\circ} 20$, Brasil.

SAOUTER, E., FEIJTEL, T.C.J. (2000). Utilización de un análisis del ciclo de vida y una evaluación de riesgos medioambientales en una evaluación integral del producto. Environmental Strategies, Nordic Workshop, Vedbaek.

ONU (2018). 24 Conferencia de las Partes en la Convención Marco de las Naciones Unidas sobre el Cambio Climático (COP24). Polonia.

OLACEFS (2019). Auditoría coordinada: energías renovables, Tribunal de Cuentas de la Unión. Brasil. Disponible en: hptt//:www.tcu.gov.br/energiasrenovaveis

OWENS, J.W. (1996). Evaluación del impacto de LCA: caso de estudio utilizando un producto para el consumidor. (LCA Impact Assessment: Case Study Using a Consumer Product.). International Journal of Life Cycle Assessment No 1, pp. 209-217.

VALLS, M. (1977). Derecho de la Energía. Editorial Abeledo Perrot, Buenos Aires.

VERCHER NOGUERA, A. (2003). Responsabilidad ambiental penal, civil y administrativa, Editorial ECOIURIS, Madrid.

VILLARDEFRANCOS ÁLVAREZ, M. (2006). La auditoría como proceso de control: concepto y tipología, Revista Ciencias de la Información No 2, La Habana.

VICENT CHULIÁ, F. (2010). Introducción al Derecho Mercantil, 22 edición, Editorial Tirant Lo Blanch, Valencia.

ZEBALlOS DE SISTO, M. (2000). El Derecho Ambiental Internacional: Esquema de su evolución, Editorial Estudio, Argentina. 